Volume 8. No. 9, September 2020

International Journal of Emerging Trends in Engineering Research

Available Online at http://www.warse.org/IJETER/static/pdf/file/ijeter116892020.pdf

https://doi.org/10.30534/ijeter/2020/116892020

\title{
Tensile Behaviour Characterization of AA5251-AA6063 joint Prepared through Friction Stir Welding process
}

\author{
U.Sudhakar $^{1}$, J.Srinivas ${ }^{2}$, M V A Raju Bahubalendruni ${ }^{3}$ \\ ${ }^{1}$ Department of Mechanical Engineering, GMRIT, Rajam, India-532127,sudhakar.u@gmrit.edu.in \\ ${ }^{2}$ Department of Mech.Engg., NIT Rourkela, Rourkela 769 008,India, srin07@yahoo.co.in \\ ${ }^{3}$ Department of Mech.Engg NIT Puducherry, Karaikal-609609, India, bahubalindruni@gmail.com
}

\begin{abstract}
Friction stir welding (FSW) is one of the most preferred welding technique to join large aluminium structures for transportation and industrial applications without investing high energy. FSW is being extensively used to joined similar and dissimilar aluminium alloys to attain better mechanical properties. The FSW process parameters such as weld speed, feed and depth of cut show significant influence on the mechanical behaviour of the weld joint. In this paper AA5251 \& AA6063 alloys have been welded through FSW at different combination of weld speed, feed and depth of cut, for which the process parameters ranges have been selected based on the thickness of the weld specimen. The specimens are prepared as per ASTM standards, and using universal testing machine the tensile behaviour is characterized. It is observed that the behaviour is quite dissimilar in nature while increasing the feed rate at different speeds for varied depth of cut. An appropriate combination of welding processes parameters to attain maximum weld strength is identified by using the regression technique.
\end{abstract}

Key words : FSW, Tensile behavior, $\mathrm{Al}$ alloys etc.

\section{INTRODUCTION}

Assembly processes consumes $20-50 \%$ of overall manufacturing cost for any product, selecting a proper assembly processes to meet the function requirements plays vital role in assembly processes planning [1-2]. Since several decades, welding is one of the promising permanent joining methods for the metals, metal matrix composites, metallic structures without compromising the mechanical strength and stiffness requirements Friction sir welding is one of the prominent welding technique used to weld Non-wieldable materials (Ex: Al7075) which are very difficult to weld by using conventional welding processes[3-8]. Thomas et al, developed friction stir welding in 1990s at the welding institute (TWI), UK, even though friction stir welding was initially developed for welding aluminium alloys, later the bandwidth has been expanded to copper, magnesium, tin, aluminium alloys composites, steels and thermo plastics materials with similar melting temperature [6,9-12]. Friction stir welding has been found in various large scale industrial applications such as (ship building, passengers trains, industrial equipment and aircraft industry) [13-16]. Friction stir welded aluminium panels used in ship structures (frames) is shown in belowFigure 1
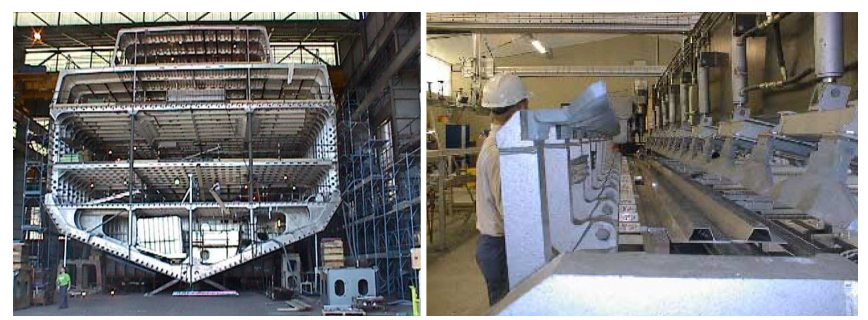

Figure 1: AL-Extrusion Panels prepared by FSW[13]

FSW is an energy efficient and environment friendly technique, since there no dust and emissions of gas during the welding operation. Most of the welding techniques reduces the mechanical properties of the weld joint compared to the base metal. However FSW is proven in minimised mechanical properties reductions, shrinkage, distortion and residual stresses in aluminum alloys(2XXX,7XXXseries) [9-12]. Fine recrystallized grain structure offers better mechanical properties such as improved tensile strength, flexural strength, impact strength, and hardness properties in FSW aluminum joints [17-23,]. Several researchers have revealed that the grain size at the weld zone of aluminum alloys can be reduced by altering the front weld parameters such as tool rotation speed and feed and their ratios [24-26,30, 31].

In this paper, an attempt is made to study the tensile behaviour of dissimilar aluminium joints (AA5251 \& AA6063 alloys) prepared at different combinations of welding processes parameters weld speed, feed and depth of cut. 


\section{FRICTION STIR WELDING AND PROCESSES PARAMETERS}

Friction-stir welding (FSW) is a solid-state permanent joining technique, where a non-consumable tool is used to seam two work pieces without melting the work piece material. While rotating the tool over the work piece, the friction between them generates heat and soften the FSW tool near region and thus fuses the two pieces and forges the hot and softened metallic zones by means of the mechanical pressure excerted by the tool. FSW is predominantly used on extruded or wrought structures of aluminium and iron, where high weld strength is main concern A revolving tool of cylindrical geometry with a profiled probe is fed between two fixed work pieces, until the shoulder of the toll meets the workpiece surface. The probe height is marginally smaller than the weld depth required for clean riding on the surface of the work piece. The tool travels along the joint line at the specified welding speed after the dwell time. Fabrication of a quality friction stir weld joint necessitates the proper tool material selection for the desired applications. The FSW processes can be either done on conventional vertical milling machine or a specified FSW machine. To carry out the experiments, a vertical milling machine shown in below Figure: $2 a$ and $2 b$ is used.

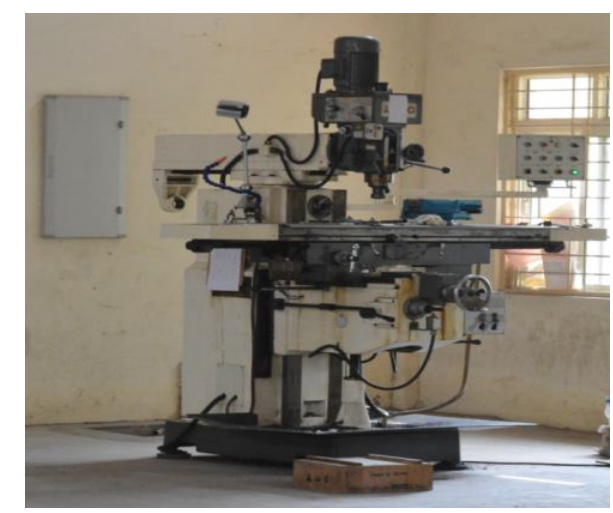

Figure 2(a): Conventional Vertical Milling

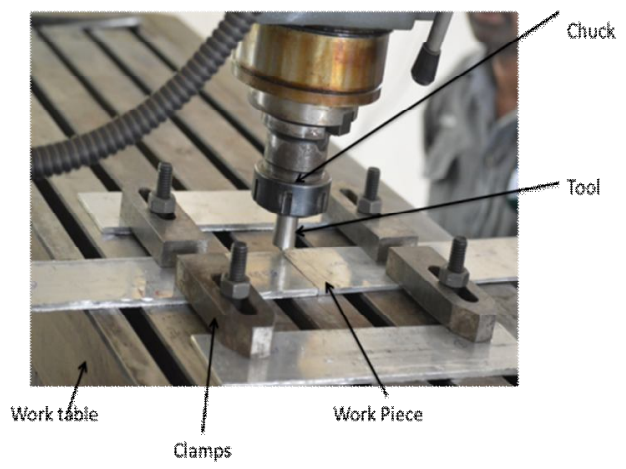

Figure 2(b): FSW of AA5251\&AA6063 on Machine to Perform FSW Vertical Milling Machine

The work pieces of aluminium dissimilar alloys i.e., AA5251 \& AA6063 are placed side by side on the plat form and are clamped in the fixture to avoid any irregular moments of work pieces during the welding operation.

Stainless tool is selected due to its advantages over other ordinary steels such as less rust and more corrosive resistant. The stainless steel tool is fixed in the spindle of the machine as shown in Figure: 3. Square cross section is selected as tool profile with depth of the probe as $2.2 \mathrm{~mm}, 2.8 \mathrm{~mm}, 3.2 \mathrm{~mm}$ and $3.5 \mathrm{~mm}$ respectively. Geometrical specification details of the tool such as pin and head dimensions are is listed in Table:1.

Table1: Specifications of the Tools used for FSW

\begin{tabular}{|c|c|c|}
\hline S.No. & Tool Specifications & $\begin{array}{l}\text { Dimensions } \\
\text { in(mm) }\end{array}$ \\
\hline 1 & Length of the tool & 100 \\
\hline 2 & Width of the square pin & 3 \\
\hline 3 & Height of square pin & $\begin{array}{c}2.2,2.8,3.2 \text { and } \\
\end{array}$ \\
\hline 4 & Diameter of the shoulder & 9 \\
\hline 5 & Diameter of the head & 12 \\
\hline 6 & Length of the shank portion & 55 \\
\hline 7 & Height of the shoulder & 2 \\
\hline 8 & Length of the head portion & 40 \\
\hline
\end{tabular}

Welding process parameters such as Feed rate $(18 \mathrm{~mm} / \mathrm{min}$, $22 \mathrm{~mm} / \mathrm{min}, 25 \mathrm{~mm} / \mathrm{min}$, and $37 \mathrm{~mm} / \mathrm{min})$, speed(760 rpm, $1130 \mathrm{rpm}$ and $1340 \mathrm{rpm}$ ) levels have been selected in accordance to the machine specifications. To analyze the influence of feed rate, at fixed depth of cut and speed, 16 sets have been considered for experimentation. The weld specimen are cut in to standard shape as per ASTM standards as shown in figure 3(a) and 3(b).

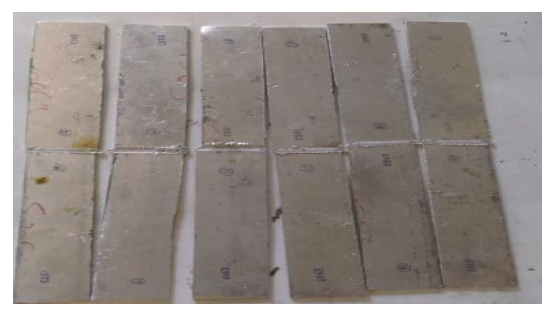

Figure3(a): AA5251 \& AA6063 Welded Joints

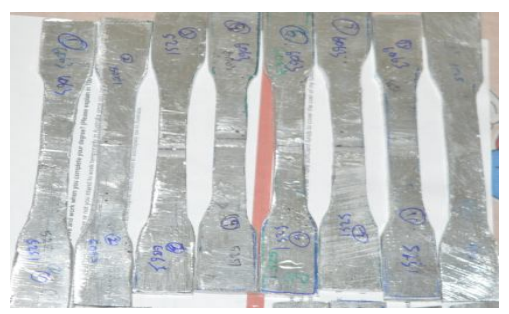

Figure3(b): Tensile Specimens as per ASTM Standards

The tensile testing of 16 welded specimen were carried out on UTM machine. The stress strain curves generated by UTM 
U.Sudhakar et al., International Journal of Emerging Trends in Engineering Research, 8(9), September 2020, $5624-5629$

machine for the first four experiments is shown in figure:4. The tensile strengths of 16 weld specimen at Depth of cut $2.2 \mathrm{~mm}$, Speed:760 rpm, and different feed rates $(18,22,25$ and 37$)$ are listed in table 3

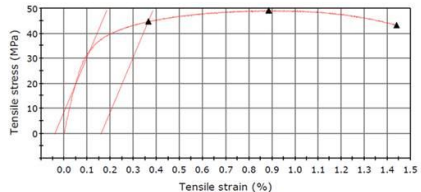

(a) At Feed Rate: $18 \mathrm{~mm} / \mathrm{min}$

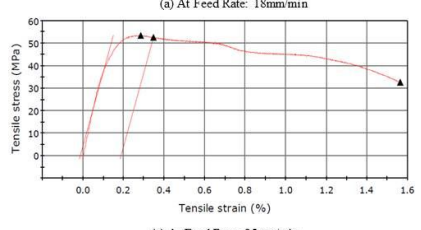

(c) At Feed Rate $25 \mathrm{~mm} / \mathrm{min}$

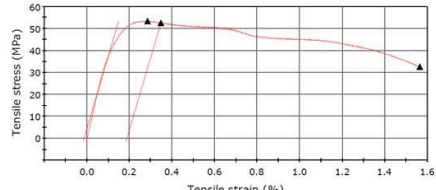

(b) At Feed Ratre: 22 mm mimi

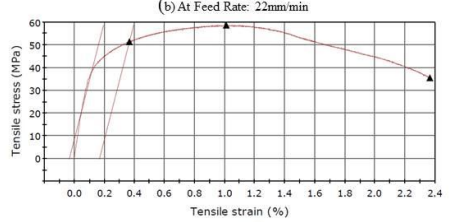

(d) At Feed Rate: 37 mmm min
Figure 4: Stress Strain Curves Obtained from UTM for at Different Feed Rate $(18,22,25,37)$ and Depth of Cut $2.2 \mathrm{~mm}$, Speed: 760rpm.

Table 2: Tensile Strengths of Weld Specimen

\begin{tabular}{|c|c|c|c|c|}
\hline S. No & $\begin{array}{c}\text { Depth } \\
\text { Of Cut } \\
(\mathbf{m m})\end{array}$ & $\begin{array}{c}\text { Speed } \\
(\mathbf{r p m})\end{array}$ & $\begin{array}{c}\text { Feed } \\
(\mathbf{m m} \backslash \mathbf{m i n})\end{array}$ & $\begin{array}{c}\text { Ultimate } \\
\text { tensile } \\
\text { strength } \\
\text { (MPa) }\end{array}$ \\
\hline 1 & 2.2 & 760 & 18 & 49.15 \\
\hline 2 & 2.2 & 760 & 22 & 52.25 \\
\hline 3 & 2.2 & 760 & 25 & 55 \\
\hline 4 & 2.2 & 760 & 37 & 58.14 \\
\hline 5 & 2.2 & 1340 & 18 & 38.75 \\
\hline 6 & 2.2 & 1340 & 22 & 36.21 \\
\hline 7 & 2.2 & 1340 & 25 & 34 \\
\hline 8 & 2.2 & 1340 & 37 & 32.54 \\
\hline 9 & 2.8 & 760 & 18 & 47.68 \\
\hline 10 & 2.8 & 760 & 22 & 49.15 \\
\hline 11 & 2.8 & 760 & 25 & 52.13 \\
\hline 12 & 2.8 & 760 & 37 & 53.22 \\
\hline 13 & 2.8 & 1340 & 18 & 65.03 \\
\hline 14 & 2.8 & 1340 & 22 & 60.12 \\
\hline 15 & 2.8 & 1340 & 25 & 57.41 \\
\hline 16 & 2.8 & 1340 & 37 & 55.58 \\
\hline
\end{tabular}

Plots are draw between Tensile Strength versus Feed rate for 2.2 depth of cut at different speeds of 760rpm and $1340 \mathrm{rpm}$ as shown Figure:5. It is observed that the tensile strength is increasing with increase in feed rate at $760 \mathrm{rpm}$ and offered highest tensile strength at $37 \mathrm{~mm} / \mathrm{min}$ feed rate, however the tensile strength is reducing with increase in feed rate at 1340 rpm. At higher speeds $(1340 \mathrm{rpm})$ the tensile strength are reduced compared to $760 \mathrm{rpm}$ and offered lowest tensile strength at $37 \mathrm{~mm} / \mathrm{min}$.

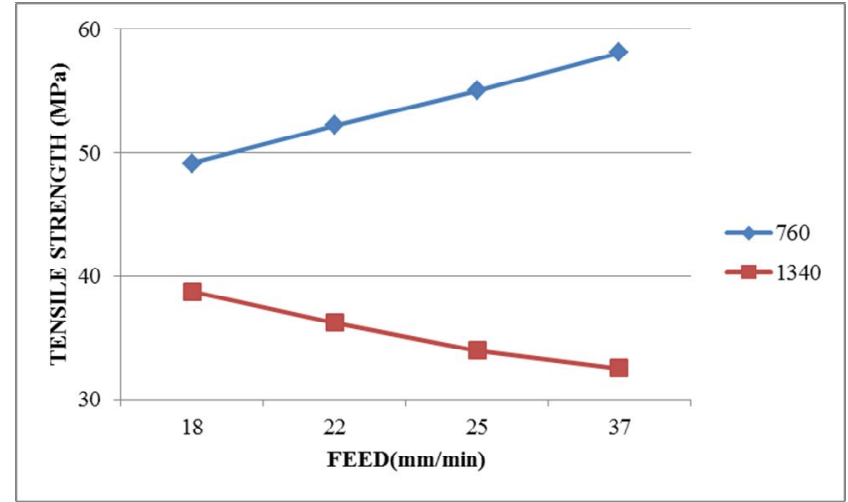

Figure 5(a): Tensile Strength vs Feed 2.2 Depth of Cut

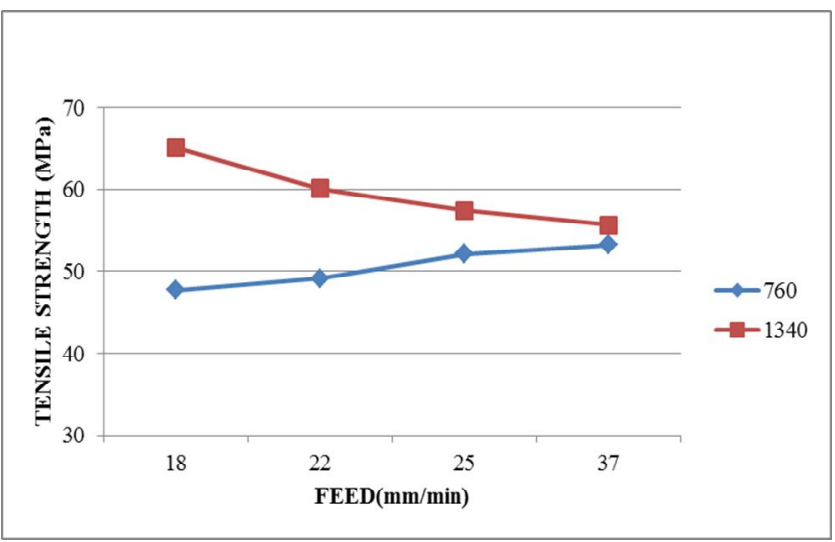

Figure 5(b): Tensile Strength vs Feed at 2.8mm Depth of cut

To understand the tensile behavior at different depth of cuts, Plots are drawn between Tensile Strength versus Feed rate for the tool with depth of cut $2.8 \mathrm{~mm}$ at different speeds $760 \mathrm{rpm}$ and $1340 \mathrm{rpm}$ as shown Figure: 5(a) and (b). It is observed that is the tensile strength is reducing at $760 \mathrm{rpm}$ with the increase in feed rate and increase in tensile strength at 1340 rpm. This behavior is quiet in contradictory nature while comparing with the tensile behavior at $2.2 \mathrm{~mm}$ depth of cut. In order to characterize the tensile behaviour, multiple experiments have been conducted with different combinations and the resulted tensile strengths are listed in table 3 .

Table 3: Experimental Tensile strength values

\begin{tabular}{|c|c|c|c|c|}
\hline S No & $\begin{array}{c}\text { Depth } \\
\text { of Cut } \\
(\mathbf{m m})\end{array}$ & $\begin{array}{c}\text { Speed } \\
(\mathbf{r p m})\end{array}$ & $\begin{array}{c}\text { Feed } \\
(\mathbf{m m} \backslash \mathbf{m i n})\end{array}$ & $\begin{array}{c}\text { UTS } \\
(\mathbf{M P a})\end{array}$ \\
\hline 1 & 2.2 & 760 & 22 & 49.15 \\
\hline 2 & 2.2 & 760 & 37 & 61.42 \\
\hline 3 & 2.2 & 1130 & 25 & 44.36 \\
\hline 4 & 2.2 & 1340 & 18 & 38.75 \\
\hline 5 & 2.2 & 1340 & 22 & 36 \\
\hline 6 & 2.8 & 760 & 25 & 27.56 \\
\hline 7 & 2.8 & 1130 & 22 & 58.69 \\
\hline
\end{tabular}


U.Sudhakar et al., International Journal of Emerging Trends in Engineering Research, 8(9), September 2020, 5624 - 5629

\begin{tabular}{|c|c|c|c|c|}
8 & 2.8 & 1130 & 37 & 61.56 \\
\hline 9 & 2.8 & 1340 & 18 & 65.03 \\
\hline 10 & 2.8 & 1340 & 25 & 57.44 \\
\hline 11 & 3.2 & 760 & 18 & 53.53 \\
\hline 12 & 3.2 & 760 & 22 & 59.13 \\
\hline 13 & 3.2 & 1130 & 37 & 41.67 \\
\hline 14 & 3.2 & 1130 & 25 & 56.84 \\
\hline 15 & 3.2 & 1340 & 37 & 53 \\
\hline 16 & 3.5 & 760 & 22 & 48.8 \\
\hline 17 & 3.5 & 760 & 22 & 61.01 \\
\hline 18 & 3.5 & 760 & 25 & 51.03 \\
\hline 19 & 3.5 & 1340 & 18 & 53.49 \\
\hline 20 & 3.5 & 1340 & 37 & 44.19 \\
\hline
\end{tabular}

\section{IMPLEMENTATION OF GENERAL REGRESSION NEURAL NETWORK}

General regression neural network (GRNN) is one of probabilistic neural network with the ability to learn in single pass from the given example data. GRNN is a very powerful tool to perform predictions for an unknown setoff input parameters by using example data. GRNN has total of four layers 1-input layer to receive input signal, 2- hidden layer to processes nonlinear transformation,3-summations layer to perform sum calculation using the outcomes of layer -2 with proper multiplication factor and 4-output layer gives the resultant outcome. GRNN has been successfully tested for various manufacturing processes to establish relation between processes parameters and the quality of the processes.[28-29]. In GRNN. Output parameter $\mathrm{Y}(\mathrm{X})$ can be estimated by the equation (1)

$$
Y(X)=\frac{\sum_{i=1}^{n} Y_{i} \exp \left(-\frac{D_{i}^{2}}{2 \sigma^{2}}\right)}{\sum_{i=1}^{n} \exp \left(-\frac{D_{i}^{2}}{2 \sigma^{2}}\right)}
$$

$$
\text { Where } D_{i}^{2}=\left(X-X_{i}\right)^{T}\left(X-X_{i}\right)
$$

$\sigma$ is the smoothing parameter which influence the relative error of predicted value, and $\mathrm{n}$ is the sample size.

From the list of 20 experiments randomly 16 set have been chosen has training sets, the remaining five sets have been identified as testing sets. Relative error between predicted and experimental values are listed in table: 4 for both training and testing data.

Table 4: GRNN Based Predicted Values and Percentage Error for Training Data Sets

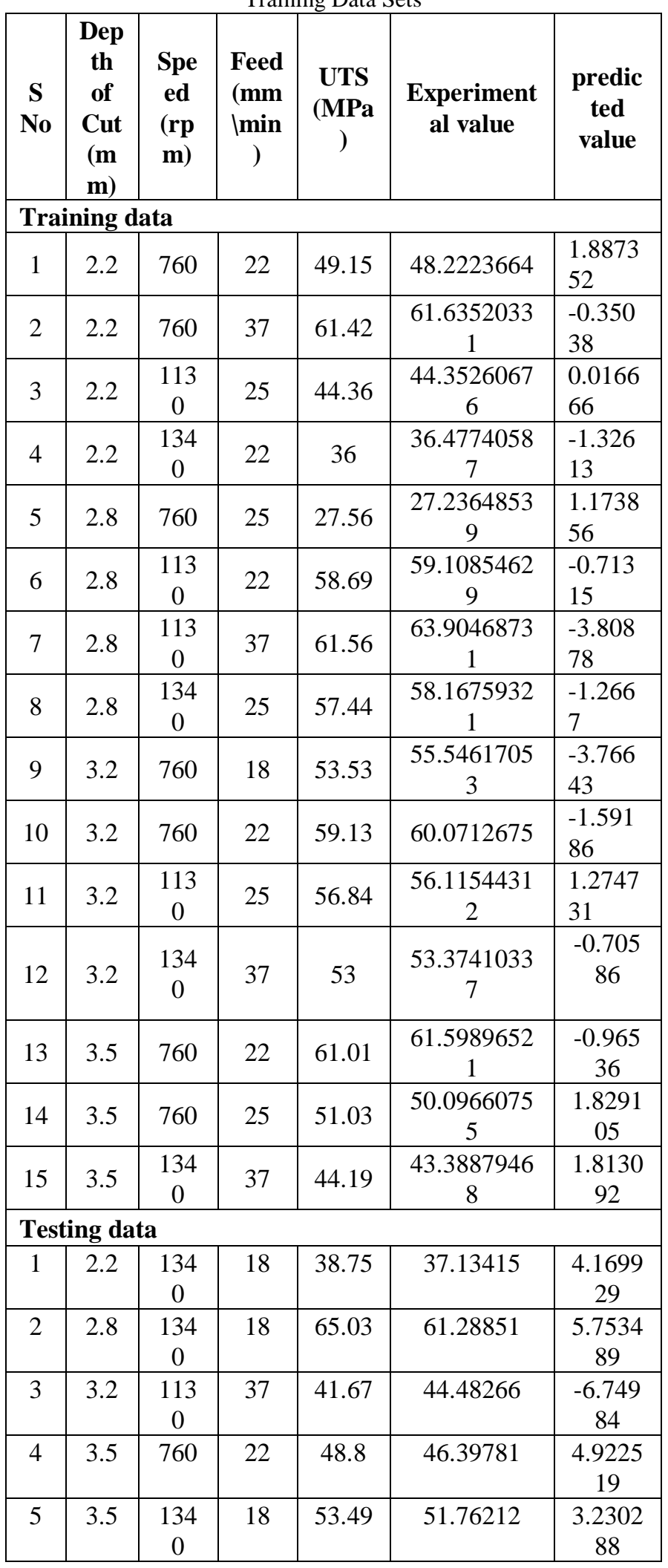




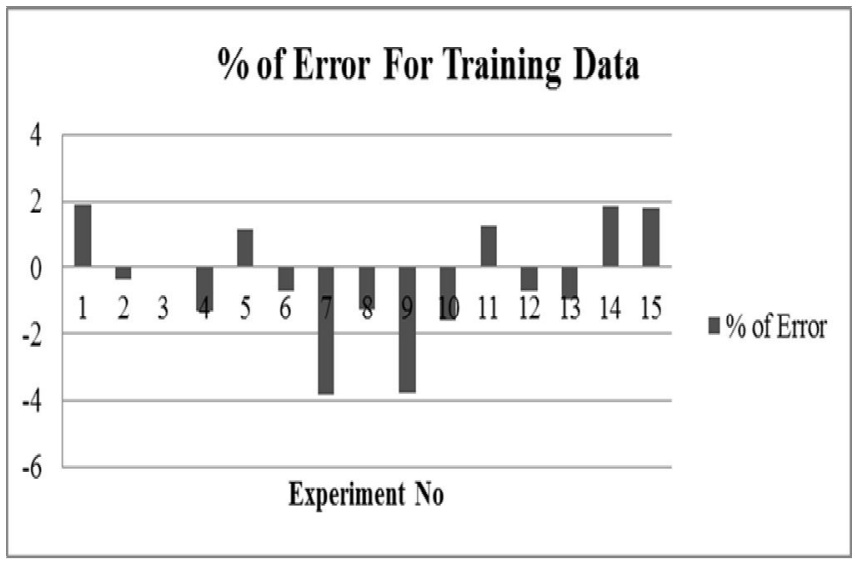

Figure 6(a): \% Error for the GRNN Training Data

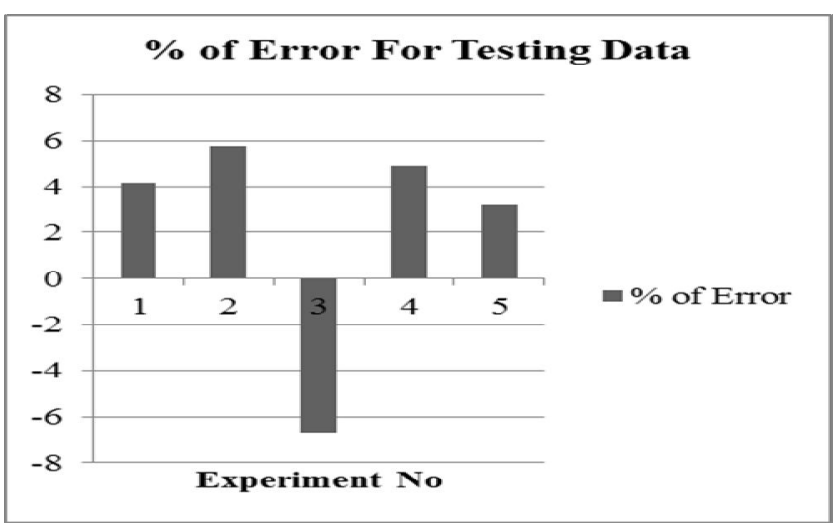

Figure 6(b): \% Error for the GRNN Testing Data

The deviation between experimental and predicted values is captured and plotted for the setoff experiments used to train the GRNN training in the Figure:6(a) and (b) presents the plot between $\%$ of Error for testing data which was not used to built the neural network. From the Figure: 7 it is observed that the $\%$ of error is -4 to 2 for training data and -7 to 6 testing data, hence the network can be used to determine the tensile strength for any set of weld processes parameters. optimal combination of weld processes parameters with 3.5 depth of cut, feed rate 25 and at 1130rpm is obtained with a tensile strength value of 69.32MPa.And physical experiment has been done with the same combination and found the tensile strength of $67.14 \mathrm{MPa}$ with a deviation of $3.24 \%$.

\section{CONCLUSION}

Friction stir welding processes has several processes parameters that influences the weld quality and its mechanical behaviour. In this present research work Aluminium alloys (AA5251 \& AA6063 ) are welded and characterized at different combination processes parameters. The conclusions from the present research work as follows.

1. Each processes parameters significantly effects the tensile strength of weld specimens.

2. The tensile strength of weld specimen increase or reduced with the positive or negative increment to feed rate or speed of the tool.
3. The GRNN is found to be efficient and effective predication tool to establish relation between weld processes parameter and tensile strength.

4. An optimum set of processes parameter have been identified through GRNN and validated through physical parameters.

\section{REFERENCES}

[1] Kalpakjian, S., \& Schmid, S. R. Manufacturing engineering and technology (p. 913). Upper Saddle River, NJ, USA: Pearson, 2014.

[2] Bahubalendruni, M. R., \& Biswal, B. B. A review on assembly sequence generation and its automation. Proceedings of the Institution of Mechanical Engineers, Part C: Journal of Mechanical Engineering Science, 230(5), 824-838, 2016.

[3] Thomas, W. M., Nicholas, E. D., Needham, J. C., Murch, M. G., Templesmith, P., \& Dawes, C. J. International patent application no (No. 9125978.8, p. 6). PCT/GB92/02203 and GB patent application, 1991.

[4] Cam, G., \& Mistikoglu, S. Recent developments in friction stir welding of Al-alloys. Journal of Materials Engineering and Performance, 23(6), 1936-1953, 2014.

[5] Thomas, W. M., \& Nicholas, E. D, Friction stir welding for the transportation industries. Materials \& design, 18(4), 269-273, 1997.

[6] Mishra, R. S., De, P. S., \& Kumar, N. Friction stir welding and processing: science and engineering. Springer. Reports, 50(1), 1-78, 2014.

[7] Defalco.J, Friction Stir Welding vs. Fusion Welding, Weld,85, p 42-44, March 2006.

[8] Arbegast J.W, Friction Stir Welding, Weld. J., 85, p 28-35, 2006.

[9] Mishra, R. S., \& Ma, Z. Y. Friction stir welding and processing. Materials Science and Engineering: R: Reports, 50(1), 1-78, 2005.

[10] Dawes, C. J., \& THOMAS, W. M. Friction stir process welds aluminium alloys: The process produces low-distortion, high-quality, low-cost welds on aluminium. Welding journal, 75(3), 41-45, 1996.

[11] Kallee, S. W., Davenport, J., \& NICHOLAS, E. D. Railway manufacturers implement friction stir welding. Welding Journal, 81(10), 47-50, 2002.

[12] Johnsen, M. R. Friction stir welding takes off at Boeing. Welding Journal, 78(2), 35-39, 1999.

[13] Ding.J., Carter, R., WLESS. LA, Nunes.K,Russell A, Suits.C.M \& Schneider.J. Friction stir welding flies high at NASA. Welding journal, 85(3), 54-59, 2006.

[14] Thomas W.M,Johnson K.I, and Wiesner C.S, Friction Stir Welding-Recent Developments in Tool and Process Technologies, Advanced Engineering Materials, 5, p 485-490, 2003. 
[15] Liu.G, Murr.L.E, Niou.C.S, McClure.J.C,and Vega.F.R, Microstructural Aspects of the Friction-Stir Welding of 6061-T6 Aluminum, Scripta Mater., 37, p 355-361, 1997.

[16] Jin.H, Saimoto.S, Ball.M, and Threadgill.P.L, Characterisation of Microstructure and Texture in Friction Stir Welded Joints of 5754 and 5182 Aluminium Alloy Sheets, Mater. Sci. Technol, 17,p1605-1614, 2001.

[17] Yan.J, Sutton.M.A, and. Reynolds.A.P, Process-Structure-Property Relationships for Nugget and HAZ Regions of AA2524-T351 Friction Stir Welds, Sci. Technol. Weld. Join., 10, p 725-736, 2005.

[18] Ren .S.R, Ma.Z.Y, and Chen L.Q, Effect of Welding Parameters on Tensile Properties and Fracture Behavior of Friction Stir Welded AlMg-Si Alloy, Scripta Mater.,56, p 69-72, 2007.

[19] Kwon.Y.J, Saito.N, and Shigematsu.I, Friction Stir Process as a New Manufacturing Technique of Ultrafine-Grained Aluminum Alloy, J. Mater. Sci. Lett., , 21, p 1473-1476, 2002.

[20] Sato.Y.S, Urata.M, and Kokowa.H, Parameters Controlling Microstructure and Hardness During Friction-Stir Welding of Precipitation- Hardenable Aluminium Alloy 6063, Metall. Mater. Trans. A, 33, p 625-635, 2002.

[21] Kwon.Y.J, Shigematsu.I, and Saito.N, Production of Ultra-Fine Grained Aluminum Alloy Using Friction Stir Process, Mater. Trans., 44, p 1343-1350, 2003.

[22] Kwon.Y.J, Shigematsu.I, and Saito.N, Mechanical Properties of Fine-Grained Aluminum Alloy Produced by Friction Stir Process, Scripta Mater., 49, p 785-789, 2003.

[23] am G. C, Serindag.H.T, akan .A.C, Mistikoglu.S, and Yavuz.H, The Effect of Weld Parameters on Friction Stir Welding of Brass Plates,Mat.-wiss. $u$. Werkstofftech.,39, p 394-399, 2008.

[24] am G.C, Mistikoglu .S, and Pakdil.M, Microstructural and Mechanical Characterization of Friction Stir Butt Joint Welded 63\% Cu- 37\% Zn Brass Plate, Weld. J., 88, p 225s-232, 2009.

[25] Ipekoglu.G, Erim.S, Gören Kiral.B, and am G.C, Investigation into the Effect of Temper Condition on Friction Stir Weldability of AA6061 Al-alloy Plates, Kovove Mater., , 51, p 155-163, 2013.

[26] Ipekoglu .G, Erim .S, and am G. C, Investigation into the Influence of Post-weld Heat Treatment on the Friction Stir Welded AA6061 Alalloy Plates with Different Temper Conditions, Metall. Mater. Trans.A, 45A, p 864-877, 2014.

[27] Subramaniam. S, Acoustic emission-based monitoring approach for friction stir welding of aluminum alloy AA6063-T6 with different tool pin profiles. Proceedings of the Institution of
Mechanical Engineers, Part B: Journal of Engineering Manufacture, 227(3), 407-416, 2013.

[28] Panda, B. N., Bahubalendruni, M. R., \& Biswal, B.

B. Optimization of resistance spot welding parameters using differential evolution algorithm and GRNN. In Intelligent Systems and Control (ISCO),IEEE 8th International Conference on pp. 50-55, 2014.

[29] Panda, B. N., Bahubalendruni, M. R., \& Biswal, B. B. A general regression neural network approach for the evaluation of compressive $\begin{array}{lll}\text { strength of } & \text { FDM }\end{array}$ prototypes. Neural Computing and Applications, 26(5), 1129-1136, 2015.

[30] Maksym Iasechko , Volodymyr Larin, Model Description of the Modified Solid State Plasma Material for Electromagnetic Radiation Protection, International Journal of Emerging Trends in Engineering Research, Volume No: 10 october 2019.

[31] Eko Julianto , Waluyo Adi Siswanto, Characteristics of Temperature changes and Stress of Float Glass under Heat Radiation, International Journal of Emerging Trends in Engineering Research, Volume 7, No. 9 September2019. 